\title{
Crystal structure of $\boldsymbol{N}$-(3-methylphenyl)(propan-2- yloxy)carbothioamide, $\mathrm{C}_{11} \mathrm{H}_{15} \mathrm{NOS}$
}

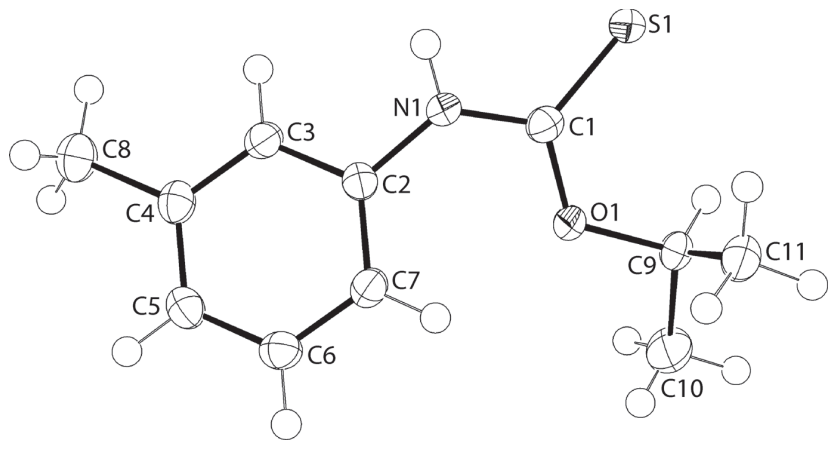

https://doi.org/10.1515/ncrs-2019-0125

Received February 20, 2019; accepted March 16, 2019; available online April 4, 2019

\section{Abstract}

$\mathrm{C}_{11} \mathrm{H}_{15} \mathrm{NOS}$, monoclinic, $\mathrm{C} 2 / c$ (no. 15), $a=21.0452(12) \AA$, $b=6.1447(4) \AA, \quad c=17.1892(10) \AA, \quad \beta=93.3520(10)^{\circ}$, $V=2219.0(2) \AA^{3}, Z=8, R_{\mathrm{gt}}(F)=0.0291, w R_{\text {ref }}\left(F^{2}\right)=0.0854$, $T=100(2) \mathrm{K}$.

\section{CCDC no.: 1903611}

The molecular structure is shown in the figure. Table 1 contains crystallographic data and Table 2 contains the list of the atoms including atomic coordinates and displacement parameters.

\section{Source of material}

All chemicals and solvents were used as purchased without purification. The reaction was carried out under ambient conditions. The melting point was determined on a Krüss KSP1N melting point meter. The IR spectrum was obtained on a Perkin Elmer Spectrum 400 FT Mid-IR/Far-IR spectrophotometer from 4000 to $400 \mathrm{~cm}^{-1}$; abbreviation: s, strong.

Preparation of the title compound: $m$-Tolyl isothiocyanate (Merck; $2.5 \mathrm{mmol}, 0.34 \mathrm{~mL}$ ) was added to $\mathrm{NaOH}$

*Corresponding author: Edward R. T. Tiekink, Research Centre for University, 47500 Bandar Sunway, Selangor Darul Ehsan, Malaysia, e-mail: edwardt@sunway.edu.my

Chien Ing Yeo: Research Centre for Crystalline Materials, School of Science and Technology, Sunway University, 47500 Bandar Sunway, Selangor Darul Ehsan, Malaysia Crystalline Materials, School of Science and Technology, Sunway

Table 1: Data collection and handling.

\begin{tabular}{ll}
\hline Crystal: & Colourless prism \\
Size: & $0.20 \times 0.11 \times 0.09 \mathrm{~mm}$ \\
Wavelength: & Mo $K \alpha$ radiation $(0.71073 \AA$ A $)$ \\
$\mu:$ & $0.26 \mathrm{~mm}^{-1}$ \\
Diffractometer, scan mode: & Bruker SMART APEX, $\omega$ \\
$\theta_{\text {max }}$, completeness: & $27.5^{\circ},>99 \%$ \\
$N\left(h k l_{\text {measured }}, N(h k l)_{\text {unique }}, R_{\text {int }}:\right.$ & $13386,2545,0.024$ \\
Criterion for $I_{\text {obs }}, N(h k l)_{\text {gt }}:$ & $I_{\text {obs }}>2 \sigma\left(I_{\text {obs }}\right), 2283$ \\
$N(\text { param })_{\text {refined }}:$ & 133 \\
Programs: & Bruker [1], SHELX [2-4], \\
& WinGX/ORTEP [5] \\
\hline
\end{tabular}

Table 2: Fractional atomic coordinates and isotropic or equivalent isotropic displacement parameters $\left(\AA^{2}\right)$.

\begin{tabular}{lrrrr}
\hline Atom & $\boldsymbol{x}$ & $\boldsymbol{y}$ & $\boldsymbol{z}$ & $\boldsymbol{U}_{\text {iso }}{ }^{*} \boldsymbol{U}_{\text {eq }}$ \\
\hline S1 & $0.35255(2)$ & $-0.21699(5)$ & $0.00951(2)$ & $0.01905(10)$ \\
O1 & $0.36789(4)$ & $0.15300(15)$ & $0.08977(5)$ & $0.01890(19)$ \\
N1 & $0.26773(5)$ & $0.03575(17)$ & $0.07219(6)$ & $0.0165(2)$ \\
H1N & $0.2418(6)$ & $-0.063(2)$ & $0.0530(8)$ & $0.020^{*}$ \\
C1 & $0.32909(5)$ & $0.00139(19)$ & $0.05886(6)$ & $0.0157(2)$ \\
C2 & $0.23881(5)$ & $0.19710(19)$ & $0.11801(6)$ & $0.0148(2)$ \\
C3 & $0.18019(5)$ & $0.1410(2)$ & $0.14645(7)$ & $0.0171(2)$ \\
H3 & 0.1625 & 0.0017 & 0.1348 & $0.021^{*}$ \\
C4 & $0.14727(6)$ & $0.2859(2)$ & $0.19151(7)$ & $0.0186(2)$ \\
C5 & $0.17389(6)$ & $0.4890(2)$ & $0.20825(7)$ & $0.0188(2)$ \\
H5 & 0.1523 & 0.5892 & 0.2395 & $0.023^{*}$ \\
C6 & $0.23190(6)$ & $0.5457(2)$ & $0.17949(7)$ & $0.0188(2)$ \\
H6 & 0.2495 & 0.6852 & 0.1911 & $0.023^{*}$ \\
C7 & $0.26468(6)$ & $0.40209(19)$ & $0.13412(7)$ & $0.0170(2)$ \\
H7 & 0.3042 & 0.4429 & 0.1143 & $0.020^{*}$ \\
C8 & $0.08445(7)$ & $0.2229(2)$ & $0.22276(9)$ & $0.0296(3)$ \\
H8A & 0.0848 & 0.2582 & 0.2784 & $0.044^{*}$ \\
H8B & 0.0776 & 0.0663 & 0.2156 & $0.044^{*}$ \\
H8C & 0.0500 & 0.3032 & 0.1946 & $0.044^{*}$ \\
C9 & $0.43606(5)$ & $0.1434(2)$ & $0.07709(7)$ & $0.0195(3)$ \\
H9 & 0.4510 & -0.0111 & 0.0796 & $0.023^{*}$ \\
C10 & $0.46806(7)$ & $0.2724(3)$ & $0.14296(9)$ & $0.0334(3)$ \\
H10A & 0.4568 & 0.2105 & 0.1929 & $0.050^{*}$ \\
H10B & 0.4538 & 0.4241 & 0.1395 & $0.050^{*}$ \\
H10C & 0.5143 & 0.2665 & 0.1393 & $0.050^{*}$ \\
C11 & $0.44799(6)$ & $0.2392(2)$ & $-0.00183(8)$ & $0.0236(3)$ \\
H11A & 0.4280 & 0.1470 & -0.0428 & $0.035^{*}$ \\
H11B & 0.4939 & 0.2468 & -0.0081 & $0.035^{*}$ \\
H11C & 0.4298 & 0.3858 & -0.0057 & $0.035^{*}$ \\
\hline & & & &
\end{tabular}

Ә Open Access. ( 2019 Chien Ing Yeo et al., published by De Gruyter. (c) BY This work is licensed under the Creative Commons Attribution 4.0 Public License. 
(Merck; $2.5 \mathrm{mmol}, 0.10 \mathrm{~g}$ ) in $i$-PrOH (Merck; $5 \mathrm{~mL}$ ) and the mixture was left for stirring at room temperature for $2 \mathrm{~h}$, followed by the addition of excess $5 \mathrm{M} \mathrm{HCl}$ solution. The resulting mixture was stirred for a further $1.5 \mathrm{~h}$. The final product was extracted with chloroform (Merck; $20 \mathrm{~mL}$ ) and left for evaporation at room temperature, yielding brown crystals after 3 weeks. M.pt: 323-325 K. IR $\left(\mathrm{cm}^{-1}\right)$ : $3220(s) v(\mathrm{~N}-\mathrm{H})$, $1491(s) v(\mathrm{C}-\mathrm{N}), 1207(\mathrm{~s}) \mathrm{v}(\mathrm{C}-\mathrm{O}), 1091(\mathrm{~s}) \mathrm{v}(\mathrm{C}=\mathrm{S})$.

\section{Experimental details}

The $\mathrm{C}$-bound $\mathrm{H}$ atoms were geometrically placed (C$\mathrm{H}=0.95-1.00 \AA)$ and refined as riding with $U_{\text {iso }}(\mathrm{H})=1.2-$ $1.5 U_{\text {eq }}(\mathrm{C})$. The $\mathrm{N}$-bound $\mathrm{H}$-atom was located in a difference Fourier map but was refined with a distance restraint of $\mathrm{N}-$ $\mathrm{H}=0.88 \pm 0.01 \AA$, and with $U_{\text {iso }}(\mathrm{H})$ set to $1.2 U_{\text {equiv }}(\mathrm{N})$. Owing to poor agreement, the $(\overline{9} 11)$ reflection was omitted from the final cycles of refinement.

\section{Comment}

A recent overview of the known crystal structures for molecules of the general formula, $\operatorname{ROC}(=\mathrm{S}) \mathrm{N}(\mathrm{H}) R^{\prime \prime}$ $\left(R / R^{\prime \prime}=\right.$ alkyl and/or aryl), i.e. the alkoxycarbothioamides, showed a high degree of concordance in their structural features [6]. Most notable was the universal adoption of a thioamide tautomer. The majority of structures featured a syn-disposition of the thione-S and thioamide- $\mathrm{N}-\mathrm{H}$ atoms. The exceptions occur when an anti-disposition of the thione$\mathrm{S}$ and thioamide- $\mathrm{N}-\mathrm{H}$ atoms is found as, for example, in the structure where $R=$ Me and $R^{\prime \prime}=4-\mathrm{C}(=0)$ Me-phenyl [7], allowing for the formation of intermolecular $\mathrm{N}-\mathrm{H} \cdots \mathrm{O}$ hydrogen bonding, and where $R=4$-pyridylphenyl and $R^{\prime \prime}=$ phenyl [8], allowing for intermolecular $\mathrm{N}-\mathrm{H} \cdots \mathrm{N}$ hydrogen bonding. Herein, as a continuation of structural studies of this class of compound $[6,7,9]$, the crystal and molecular structures of the compound with $R={ }^{\mathrm{i}} \operatorname{Pr}$ and $R^{\prime \prime}=3$-Me-phenyl are described.

The molecular structure is shown in the figure $(70 \%$ displacement ellipsoids) and features the normally observed [6] syn-disposition of the thione-S and thioamide- $\mathrm{N}-\mathrm{H}$ atoms. In accord with expectation, the central $\mathrm{C} 1, \mathrm{~N} 1, \mathrm{O} 1, \mathrm{~S} 1$ residue is planar with the r.m.s. deviation being $0.0044 \AA$. The dihedral angle between the central plane and appended 3-tolyl group is $23.06(5)^{\circ}$. Evidence for the thioamide tautomer is found in the magnitude of the $\mathrm{C} 1=\mathrm{S} 1$ [1.6772(12) $\AA$ ] and C1-N1 [1.3412(15) $\AA$ ] bond lengths, and in the location of the thioamide- $\mathrm{N}-\mathrm{H}$ atom in the crystallographic refinement. The angles subtended at the quaternary- $\mathrm{C} 1$ atom follow the expected trends with $\mathrm{S} 1-\mathrm{C} 1-\mathrm{O} 1\left[_{\left.124.81(9)^{\circ}\right]}\right]$ being wider than S1-C1-N1 [121.82(9) $\left.{ }^{\circ}\right]$ and each of these being wider than O1-C1-N1 [113.36(10) ${ }^{\circ}$.
The syn-disposition of the thione-S1 and thioamide$\mathrm{N}-\mathrm{H}$ atoms allows for the formation of thioamide- $\mathrm{N}-$ $H \cdots S$ (thione) hydrogen bonds in the molecular packing

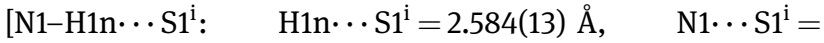
3.4352(11) $\AA$ with angle at $\mathrm{H} 1 \mathrm{n}=167.0(11)^{\circ}$ for symmetry operation i: $1 / 2-x,-1 / 2-y,-z]$. As these occur between centrosymmetrically related molecules, eight-membered $\left\{\cdots \mathrm{HNCS}_{2}\right.$ synthons ensue. Intermolecular points of contact of the type tolyl-C-H $\cdots \pi \quad\left[\mathrm{C} 6-\mathrm{H} 6 \cdots \mathrm{Cg}(\mathrm{C} 2-\mathrm{C} 7)^{\mathrm{ii}}\right.$ : $\mathrm{H} 6 \cdots \operatorname{Cg}(\mathrm{C} 2-\mathrm{C} 7)^{\mathrm{ii}}=2.80 \AA, \quad \mathrm{C} 6 \cdots \operatorname{Cg}(\mathrm{C} 2-\mathrm{C} 7)^{\mathrm{ii}}=3.4597(13) \AA$ and angle at $\mathrm{H} 6=127^{\circ}$ for ii: $\left.1 / 2-x, 1 / 2+y, 1 / 2-z\right]$ and parallel $\mathrm{C}=\mathrm{S} \cdots \pi\left[\mathrm{C} 1-\mathrm{S} 1 \cdots \mathrm{Cg}(\mathrm{C} 2-\mathrm{C} 7)^{\mathrm{iii}}\right.$ : $\mathrm{S} 1 \cdots \mathrm{Cg}(\mathrm{C} 2-$ $\mathrm{C} 7)^{\mathrm{iii}}=3.8929(6) \AA, \quad \mathrm{C} 1 \cdots C g(\mathrm{C} 2-\mathrm{C} 7)^{\mathrm{iii}}=3.9582(12) \AA \quad$ and angle at $\mathrm{S} 1=79.85(4)^{\circ}$ for iii: $\left.1 / 2-x, 1 / 2-y,-z\right]$, each involving the 3-tolyl ring, serve to link molecules into a supramolecular layer in the $b c$-plane. Layers stack along the $a$ axis direction without directional interactions between them.

The most closely related structures in the literature are the polymorphic structures $\operatorname{EtOC}(=S) N(H)$ (3-Me-phenyl) $[6,10]$, i.e. where ${ }^{\mathrm{i}} \mathrm{Pr}$ is substituted with Et; both polymorphs are monoclinic. In the $P 2_{1} / c$ form [6], there are two independent molecules in the asymmetric unit whereas in the C2/c form [10], one molecule comprises the asymmetric unit. Not unexpectedly, similar trends in conformation and geometric parameters are evident, along with supramolecular association via $\{\cdots \mathrm{HNCS}\}_{2}$ synthons, as described above.

Acknowledgements: The University of Malaya's X-ray laboratory is thanked for the intensity data. Sunway University is thanked for support of crystal engineering and biological studies of thiocarbamides and their metal complexes.

\section{References}

1. Bruker. APEX2 and SAINT. Bruker AXS Inc., Madison, WI, USA (2008).

2. Sheldrick, G. M.: SADABS. University of Göttingen, Germany (1996).

3. Sheldrick, G. M.: A short history of SHELX. Acta Crystallogr. A64 (2008) 112-122.

4. Sheldrick, G. M.: Crystal structure refinement with SHELXL. Acta Crystallogr. C71 (2015) 3-8.

5. Farrugia, L. J.: WinGX and ORTEP for Windows: an update. J. Appl. Crystallogr. 45 (2012) 849-854.

6. Jotani, M. M.; Yeo, C. I.; Tiekink, E. R. T.: A new monoclinic polymorph of $\mathrm{N}$-(3-methylphenyl) ethoxycarbothioamide: crystal structure and Hirshfeld surface analysis. Acta Crystallogr. E73 (2017) 1889-1897.

7. Ho, S. Y.; Bettens, R. P. A.; Dakternieks, D.; Duthie, A.; Tiekink, E. R. T.: Prevalence of the thioamide $\{\cdots \mathrm{H}-$ $\mathrm{N}-\mathrm{C}=\mathrm{S}\}_{2}$ synthon solid-state (X-ray crystallography), 
solution (NMR) and gas-phase (theoretical) structures of $\mathrm{O}$-methyl- $\mathrm{N}$-aryl-thiocarbamides. CrystEngComm 7 (2005) 682-689.

8. Xiao, H.-L.; Wang, K.-F.; Jian, F.-F.: (4-Pyridyl)methyl Nphenylthiocarbamate. Acta Crystallogr. E62 (2006) 0285202853.
9. Yeo, C. I.; Tiekink, E. R. T.: Crystal structure of $\mathrm{N}$-(2methylphenyl)ethoxycarbothioamide, $\mathrm{C}_{10} \mathrm{H}_{13}$ NOS. Z. Kristallogr. NCS 233 (2018) 299-301.

10. Tadbuppa, P.; Tiekink, E. R. T.: Crystal structure of o-ethyl $\mathrm{N}$-( $m$-tolyl)thiocarbamate, $\mathrm{SC}\left(\mathrm{OC}_{2} \mathrm{H}_{5}\right) \mathrm{NH}\left(\mathrm{C}_{6} \mathrm{H}_{4} \mathrm{CH}_{3}\right)$. Z. Kristallogr. NCS 220 (2005) 395-396. 